\title{
"Si yo cerrara los ojos, sería una niña española, catalana... de aquí". Representaciones, identidades y filiaciones en la adopción internacional en Cataluña ${ }^{1}$
}

\author{
"If I closed my eyes, she would be a Spanish girl, \\ a Catalan girl... a girl from here». Representations, identities \\ and filiations in inter-country adoption in Catalonia
}

\author{
Verónica Anzil \\ Universitat Rovira I Virgili. Tarragona
}

\section{RESUMEN}

En este trabajo se exploran los imaginarios de la sociedad catalana con respecto a la adopción internacional y a algunos de sus protagonistas. Se analizan cerca de ochocientos artículos publicados en dos de los periódicos de mayor tirada en Cataluña, con el objetivo de reconstruir los estereotipos que la prensa contribuye a modelar y [re]crear acerca de la adopción internacional, las personas adoptantes y adoptadas, y las sociedades de origen y de recepción. Las construcciones resultantes se comparan con el contenido de las entrevistas realizadas con padres, madres, jóvenes adoptados, educadores, profesionales y responsables de asociaciones. Habiendo comprobado la existencia de ciertos conflictos entre estas construcciones, se investigan las estrategias que los actores involucrados construyen para resolverlos.

Palabras clave: Adopciones internacionales, Representaciones, Identidades, Pertenencia nacional, Cataluña.

\section{SUMMARY}

This paper explores representations that are present in Catalan society with regard to intercountry adoption and some of the people involved. In light of media portrayals affecting the [re]construction and transmission of collective "imaginaries" on adoption, adopters, adoptees and the originating and receiving countries, a discourse analysis was undertaken in nearly eight hundred articles published in two of the major newspapers in Catalonia. The resulting constructs were compared with the content of the interviews with parents, adoptees, educators, professionals and

\footnotetext{
${ }^{1}$ Este artículo es una versión resumida y revisada de la investigación "Si yo cerrara los ojos y la tuviera delante, o sea, sin mirarla... sería una niña totalmente española, catalana, de aquí’. Representaciones, identidades y filiaciones en la adopción internacional en Cataluña", realizada con el apoyo del Departament d'Universitats, Recerca $i$ Societat de la Informació de la Generalitat de Catalunya para optar a la obtención del grado doctoral en la Universidad Rovira i Virgili.
} 
leaders of associations. Having established the existence of certain conflicts among these constructs, the strategies which participants employ in order to solve them, were investigated.

Key words: Inter-country Adoption; Stereotypes; Identities, National Belonging, Catalonia.

\section{INTRODUCCIÓN}

Entre 1998 y 2011 más de 12.000 menores nacidos y adoptados en el extranjero llegaron a Cataluña (IDESCAT 2003, 2009 y 2011). Entre ellos prevalecen los provenientes de países del llamado "Tercer mundo", en los que la mayoría de la población es portadora de fenotipos diferentes a los predominantes en Cataluña, característica que comparten con otros inmigrantes presentes en la comunidad autónoma.

La adopción (específicamente la internacional) evoca no sólo una serie de preguntas sobre "raza", cultura, nación, genes, parentesco y pertenencia, sino que, desde un enfoque más global, nos interroga acerca de las políticas de los países de origen y los receptores, y sus desigualdades, el post-colonialismo y las relaciones internacionales (Howell 2009: 151). Ha sido definida además como uno de los objetos de estudio que, "junto a las tecnologías reproductivas y el capitalismo global constituyen un mayor desafío a los estudios de parentesco, sobre todo en su dimensión de proceso no biológico de procreación" (Franklin y McKinnon 2001, citado en Grau Rebollo 2004).

Muchos autores sostienen que la temática ha estado y está en el "punto de mira" de diversas disciplinas, cada una de las cuales complementa y/o cuestiona a las demás en su intento de comprensión de este objeto tan polifacético (Dalen 2001; Howell 2009; Palacios y Brodzinsky 2010; Grau Rebollo 2011, entre otros). En 2001 Monica Dalen señaló ciertas diferencias entre los temas de investigación elegidos por quienes estudian las adopciones internacionales en diferentes zonas del mundo. En aquellos países con presencia de minorías étnicas desde ya hace tiempo — como los EE. UU.- los investigadores se centran sobre todo en el "sentido étnico de pertenencia, identidad y auto-confianza" de las personas adoptadas. Muchos de estos trabajos, que hablan de "razas" — caucásica, negra, oriental—, de "identidades coreano-americanas", "nativo-americanas", "afro-americanas", "chino-americanas" etc., debaten acerca de las adopciones "transraciales" — domésticas o internacionales- y argumentan acerca de la viabilidad o no de estas experiencias (Simon y Alstein 1981, 1987, 1992; Grotevant 1997). Sin embargo, la pertenencia de los adoptados internacionales a los EE. UU. como estado-nación no entra nunca en discusión. En contraste, la mayoría de los trabajos analizados provenientes de los países nórdicos se centran en la dicotomía vivida por los adoptados internacionales al sentirse suecos, noruegos, daneses, pero ser vistos como chinos, africanos, colombianos, etc. (Howell 2004; Hübinette 2004; Yngvesson 2007, 2010). Palacios y Brodzinsky señalan una dicotomía similar:

Consider the experience of the transracially-placed child growing up in the US or UK, where there is considerable racial and cultural diversity, versus in the Scandinavian countries, where there is much more homogeneity in terms of race and culture. The first group of children is likely to have many more opportunities to learn about their racial and cultural heritage, to meet others who share a similar racial and cultural origin, and 
to develop appropriate strategies for coping with racial prejudice than is the second group of children (Palacios y Brodzinsky 2010: 279).

Los mismos autores señalan que poco se ha investigado en España acerca de lo que ellos llaman "la base contextual de la integración social" de los menores adoptados, refiriéndose a su inclusión en su grupo de pares, escuela y comunidad de adopción y a la manera en que estos niños y jóvenes negocian sus diferencias (Palacios y Brodzinsky 2010: 279-280). Con algunas excepciones, la adopción transnacional en España —y dentro de ella, Cataluña- comenzó en 1990, pero se incrementó de manera significativa durante la segunda mitad de esa década. A diferencia de lo señalado para los países de la península escandinava, donde los menores llegaban a una sociedad receptora fenotípicamente muy homogénea, por lo que eran inmediatamente reconocidos como personas adoptadas en el extranjero (Sæetersdal y Dalen 2000; Dalen 2001), en Cataluña "las adopciones internacionales [AI] comenzaron a hacerse manifiestas al mismo tiempo que los nuevos movimientos migratorios de países no comunitarios, con unos signos visibles de sus orígenes" (Marre y Bestard 2004: 42). ¿Cuál es entonces la percepción de esa sociedad hacia esos menores y jóvenes adoptados en el extranjero? ¿Ocupan un lugar diferente al de las otras personas «inmigrantes" en el imaginario social?

\section{OBJETIVOS, CONCEPTOS Y METODOLOGÍA}

Me propuse explorar estos temas a través de datos provenientes de miembros de las familias adoptivas, maestros, profesionales y técnicos de la adopción, y entorno social general de las personas adoptadas internacionalmente. Los objetivos de este trabajo de investigación son: explorar las representaciones de la sociedad catalana con respecto a la adopción internacional y a las personas adoptantes y adoptadas; estudiar la imagen que estos niños, niñas y jóvenes nacidos y adoptados en el extranjero tienen de sí mismos, de sus familias, de la sociedad que les rodea, y del lugar que ocupan dentro de esta sociedad, así como la/s pertenencia/s nacional/es a la/s que se adscriben, a partir de las percepciones de personas de su entorno más cercano; averiguar cuáles son las identificaciones adjudicadas a estos niños, niñas y jóvenes por su entorno social; y por último, de comprobarse algún tipo de conflicto entre estas construcciones, investigar las estrategias que los actores crean para resolverlo.

Para conseguir esos objetivos, la población con la que me propuse trabajar debía reunir ciertas características: ser personas nacidas y adoptadas en otros países; tener características fenotípicas diferentes a las de su familia adoptiva y a la mayoría de la sociedad receptora; tener como mínimo 8 años (Brodzinsky 1987, 1990; Grotevant 1997; Triseliotis 1973$)^{2}$; y residir con su familia en el Camp de Tarragona ${ }^{3}$. Me había pro-

\footnotetext{
${ }^{2}$ Brodzinsky (1987), por ejemplo, sostiene que la edad a la que el menor empieza a percibir el significado de la adopción y de las particularidades asociadas a la misma se ubica entre los 8 y los 11 años de edad.

${ }^{3}$ Se seleccionó esta zona — que comprende las comarcas que de Alt Camp, Tarragonés y Baix Camp- por la existencia de una red de contactos previa, y por tratarse de un territorio abarcable por un solo investigador en una investigación cualitativa.
} 
puesto entrevistar a las personas adoptadas, pero el estudio de la bibliografía previa sobre el tema y los datos estadísticos relativos a las edades predominantes entre estas personas (en 2008 más del 80\% tenía menos de 7 años) hicieron que me replanteara esta decisión. A esto se agregó el convencimiento de mi falta de preparación profesional para abordar temas tan delicados con personas tan jóvenes. Me propuse entonces utilizar otras fuentes, por lo que decidí buscar informantes en el entorno cercano de estos menores.

A medida que el estudio avanzaba, iba apreciando que mis reflexiones iban siempre hacia el terreno de la identidad de estos niños, niñas y jóvenes. A pesar de reconocer la naturaleza elusiva y problemática del concepto, tuve que buscar una definición lo suficientemente clara y operativa, coherente con el marco y objetivos del estudio. En este contexto, lo que llamo identidad es un proceso en marcha más que un resultado y, por lo tanto, algo siempre inacabado, en construcción. En definitiva, retuve la definición enunciada por Joan Prat Carós, donde la identidad es entendida como:

El mecanismo o proceso clasificatorio (o auto-clasificatorio), mediante el cual definimos el who is who, individual y colectivo, a partir de imágenes culturales ya existentes y de modelos referenciales previos. Gracias a las marcas identitarias y a la aplicación de sistemas de afiliación o exclusión, podemos definir y situar el yo y el tú, el nosotros y el vosotros (o ellos) en el complejo mundo de interacciones biológicas, sociales, culturales o simbólicas en las que estamos insertos (Prat 2011).

Además, fue necesario buscar algunos conceptos subsidiarios: así, entiendo por "auto-identificación" la manera en que los niños, niñas y jóvenes —nacidos y adoptados en el extranjero- se describen a sí mismos, y a su lugar en esta sociedad. Quiero aclarar que en esta investigación, esa "auto-identificación" fue reconstruida principalmente a partir del discurso de adultos del entorno cercano de los niños, ya que sólo pude entrevistar a 3 jóvenes. Por otro lado, utilizo la noción de identificación externa para denominar a aquellas representaciones reflejadas principalmente en la prensa acerca de esos niños, niñas y jóvenes, y del lugar que se les atribuye. Pero no puede obviarse que esa identificación del yo - y del "nosotros" - a la que llamo "auto-identificación", tiene lugar en un juego dialéctico con las identificaciones externas, y que ambas construcciones pueden o no converger. Por lo tanto, se toman en cuenta las nociones de "auto-identificación" y de identificación externa, pero también la coherencia o incoherencia entre ambas. Los tres aspectos del proceso identitario tienen la misma importancia en esta investigación.

Para la reconstrucción de la "auto-identificación" de los menores y jóvenes me basé en 41 entrevistas semi-dirigidas: 26 entrevistas a uno o más miembros de familias adoptivas biparentales o monoparentales, con hijos biológicos y/o adoptivos, residentes en el Camp de Tarragona (se incluyen aquí las 3 entrevistas realizadas a jóvenes adoptados). Para contactar a las familias susceptibles de participar en el trabajo utilicé mis redes sociales personales y, al finalizar cada entrevista, preguntaba a los informantes si podían ponerme en contacto con otras familias adoptantes conocidas. A las mantenidas con miembros de familias adoptivas se agregaron 12 entrevistas a educadores de cinco centros a los que acuden niños y niñas adoptados en el extranjero, y 3 entrevistas a profesionales implicados en distintos pasos del proceso de AI. En un prin- 
cipio sólo me acerqué a aquellos centros (primarios y secundarios, públicos y concertados) a los que acudían los hijos e hijas de las familias que iba entrevistando, con el objeto de recoger los testimonios tanto de sus educadores actuales, como de aquellos que les habían recibido cuando se incorporaron al centro. Más adelante decidí utilizar los centros educativos para ampliar el abanico de familias, por lo que solicité autorización a las direcciones de los centros para entrevistar a aquellos educadores que tuvieran o hubieran tenido estudiantes adoptados en el extranjero. Para entrevistar a los profesionales involucrados en la AI, me puse en contacto con las filiales tarraconenses de las instituciones en las que trabajan.

Los 31 hijos e hijas adoptivos de esas familias, provenientes de países de América Latina —45\%—, Asia —29\%—, África —23\%— y Europa del Este —3\%—, tenían entre 7 y 21 años en el momento de realización de la entrevista; fueron adoptados cuando tenían entre dos meses y catorce años, y hacía entre 2 meses y 18 años que vivían con sus familias adoptivas en diversas localidades del Camp de Tarragona.

Para cumplir con los objetivos que conciernen a las representaciones de la sociedad catalana con respecto al tema, hice una recolección y análisis sistemáticos de los 796 artículos publicados en La Vanguardia — diario catalán de mayor tirada en la comunidad autónoma - y El País - periódico nacional de mayor tirada en Cataluña entre $1997^{5}$ y 2011, utilizando las palabras clave "adopción internacional". A ese análisis se agregó el de publicaciones del Institut Català de l'Acolliment $i$ de l'Adopció (ICAA), guías sobre adopción de algunas comunidades autónomas, publicaciones periódicas de algunas Entidades Colaboradoras de la Adopción Internacional (ECAI) y asociaciones de familias adoptantes, y las legislaciones autonómica, nacional e internacional vigentes, así como los debates parlamentarios de leyes relacionadas al tema de esta investigación.

\section{RESULTADOS}

\section{LA ADOPCIÓN INTERNACIONAL}

La legislación vigente establece que la adopción internacional, medida de protección utilizada cuando se han debido descartar otras alternativas, tiene como principal objetivo integrar a un niño desamparado en una familia que pueda asegurarle su pleno desarrollo. Pero cuando cualquiera de las fuentes utilizadas describe el proceso de AI, el discurso suele centrarse en la satisfacción de los deseos de aquellos adultos que, o bien porque han experimentado dificultades para concebir — por razones médicas, por edad, por no estar en pareja, etc.—, o bien por "solidaridad", desean adoptar a un menor. Todas las fuentes son portadoras de un mensaje que desplaza al principal personaje de esta medida de protección, la infancia, de su rol protagónico. La

\footnotetext{
${ }^{4}$ Según datos de la Oficina para la justificación de la difusión —http://www.ojd.es— consultado el 22 de mayo de 2008.

${ }^{5}$ La primera fecha coincide con el primer año en que se instauró la obligatoriedad del Certificado de Idoneidad para todos los solicitantes de adopción, permitiendo disponer de estadísticas completas. El análisis se realizó en 2012, por lo que el último año completo incorporado fue 2011.
} 
insistencia de los especialistas en recordar a una familia que el único derecho es el del niño, marca una distancia en el discurso de los profesionales y el de los legisladores, quienes persisten en el uso de la expresión "derecho a la adopción", "equiparación de derechos" etc. —coincidiendo con lo hallado por Vilaginés Ortet (2007: 89).

Por otro lado, para muchos de los solicitantes la AI es percibida como "el último recurso", coincidiendo con lo descrito por Telfer (en Howell 2009: 160), pero no con lo constatado por Brancós Coll (2008: 55). La mayoría de las familias entrevistadas declara haber optado por tener hijos adoptivos después de haber experimentado dificultades para concebir, tras haberlo intentado recurriendo a técnicas de reproducción asistida, y después de haber descartado la adopción nacional. Ahora bien, en los discursos, esta idea de la adopción como último recurso aparece frecuentemente asociada con la noción del lazo de parentesco biológico como el único "verdadero". Esto relega la adopción a una posición de filiación "de segunda", cuestionándose así la legitimidad de la familia adoptiva, ya que los lazos de parentesco que crea no son como los genético-biológicos — los "de sangre»—, los únicos considerados "verdaderos," "Válidos" o "normales". Esto se pone en evidencia cuando algunos de los padres y madres entrevistados, así como muchos de los citados en los artículos de prensa analizados hablan de "mis hijos" para nombrar exclusivamente a sus hijos biológicos, o "su madre verdadera", para hablar de la madre de origen de sus hijos, por ejemplo. A pesar de ser protagonistas de un modelo de familia basado en la relación - Nurture-, hay adoptantes que parecen tener una visión "biologizante" del parentesco — Nature — , en el que los lazos válidos se basan en el significado otorgado a la "Sangre" y/o "genética" compartidas. Es destacable que la ley catalana de adopción señala que la adopción "imita a la naturaleza" ${ }^{6}$, e imitando a la naturaleza, crea lazos de parentesco (Marre y Bestard 2004: 39-40).

Otro rasgo reincidente en las fuentes analizadas es la asimilación entre el proceso de AI y la gestación/parto. Este paralelismo, ya mencionado por varios autores (Ouellette y Belleau 1999: 81; Belleau 2000: 313; Howell y Marre 2009: 205-211), además de ser un nuevo indicio de la necesidad de usar el cuadro "normalizador" del parentesco biogenético, sugiere que los adoptantes consideran a la adopción como una ruptura en la vida de su hijo, siguiendo la línea de "la ruptura del vínculo de filiación pre-existente" establecida en la legislación de países como España, donde la única adopción legalmente reconocida es la adopción plena. Se trataría de un "renacimiento" que borraría todo pasado no compartido con su nueva familia. En los relatos aparecen ciertos "ritos" que facilitarían ese pasaje: el primer baño del menor a su llegada al alojamiento de la familia, su presentación en sociedad al llegar al aeropuerto, el festejo anual de la fecha del primer encuentro. Esta idea de la adopción como ruptura, también se hace evidente en la descripción de los primeros días de convivencia, durante los cuales muchos de los adoptantes dicen haber notado un "cambio radical" en los niños, estableciendo un "antes" y un "después" en la vida de sus hijos e hijas. Esto es lo opuesto a lo que los profesionales entrevistados dicen intentar transmitir en el proceso de AI, describiendo la adopción como "una coma" en la vida del menor.

Pero indudablemente, el tipo de vocabulario más utilizado en la prensa para hablar de AI es el lenguaje comercial o mercantil, en consonancia con lo que Constable

\footnotetext{
${ }^{6}$ Ley 37/1991, del 30-12-1991 y ley 9/1998, del 15-07-1998, del Código de familia.
} 
(2009: 50) ha llamado "mercantilización de la intimidad". En muchas ocasiones, el discurso es idéntico al usado para las operaciones comerciales: se habla de la "oferta" y "demanda de niños", de "mercado de la adopción", de "países exportadores de niños en adopción", o se usa la palabra "transacciones" para hacer referencia a las adopciones, aunque sean legales. Este lenguaje aparece muy asociado con la imagen de los menores que emerge de estos artículos periodísticos, reforzando el papel pasivo que se les atribuye en los procesos de AI. Cuando el discurso analizado es el de las 25 familias entrevistadas, este lenguaje es más infrecuente, aunque no está del todo ausente.

\section{LOS PAÍSES DE ORIGEN}

Los artículos de prensa analizados señalan cuatro grandes regiones como los lugares de origen de los menores y jóvenes adoptados: América Latina, Asia, Europa del Este y África.

América Latina — citada a menudo como si fuera un país - se asocia con guerras, violencia, inseguridad e inestabilidad política. La pobreza y la lentitud de los trámites también son frecuentemente señaladas.

Nunca se cita al continente asiático como un todo, sino que se habla de algunos de sus países. El imaginario construido por la prensa sobre China es bastante constante: al principio se mencionan la política del hijo único, y los orfanatos saturados de niñas — cuyas condiciones de vida se describen como «infrahumanas»-, pero a partir del momento en que los adoptantes españoles comenzaron a enviar sus solicitudes a China, se habla de "rapidez", "transparencia" y "eficacia". Esta imagen coincide plenamente con la brindada por las familias entrevistadas y por lo hallado por Marre (2007: 77), aunque es relativizada por las observaciones de Vich (2010: 261-278).

"Europa del Este" es otra de las áreas frecuentemente nombradas como un todo homogéneo, aunque también hay artículos que describen a algunos de los países de la región. Los artículos que aluden a Rusia mencionan procesos "rápidos", "serios", aunque "caros". Las irregularidades relatadas y las malas condiciones de vida de los orfanatos son minimizadas, y se valora "el factor humano".

África, como un todo homogéneo, es descrita como "el Cuarto Mundo", y presentada como "la gran reserva del desamparo"; se alude a su falta de infraestructuras y su inseguridad jurídica. Sin embargo, la imagen general de Etiopía es muy buena, a pesar de que durante los últimos años analizados el país había endurecido los requisitos exigidos a los candidatos a la AI, y había cerrado las adopciones "por libre" debido a aspectos dudosos descubiertos en algunos procesos. La precariedad de su sistema judicial, explícitamente mencionada, no parecía incomodar ni a los solicitantes, ni a las autoridades españolas o autonómicas, como lo demuestra el hecho de que en muy poco tiempo pasara a ocupar el segundo puesto en número de AI constituidas.

En resumen, al describir a los países de origen de los menores adoptados por españoles en el extranjero, la prensa habla de guerras, inestabilidad, miseria, falta de seguridad, violencia, corrupción gubernamental, devastación, extrema pobreza. No obstante, tres países cuentan con imágenes muy positivas: China, Rusia y Etiopía, los tres que encabezaron las listas de AI en los últimos años anteriores al análisis. 
Sorprende el contraste entre las opiniones de las familias sobre el país de origen de sus hijos y sobre sus habitantes: mientras que las primeras suelen coincidir con las imágenes publicadas por la prensa — precaria situación económica, inestabilidad política e inseguridad- los habitantes son descritos en términos generalmente muy positivos. Que los adoptantes tengan una imagen predominantemente negativa de las condiciones de vida de los ciudadanos de los países de origen de sus hijos sería coherente con la convicción expresada por muchos de ellos de haber "rescatado" a sus hijos e hijas a través de la adopción internacional, narrativa compartida con otros adoptantes euro-norteamericanos (Yngvesson 2010: 32). Esta idea de rescate les permitiría pensar que los niños provenientes de esos países siempre estarán mejor con una familia de aquí, que si se quedaran en sus lugares de origen. Además, como hay muchos padres y madres que siguen hablando de sus hijos como si siguieran siendo ciudadanos de sus países de origen — como desarrollaré más adelante-, la necesidad de incluirlos en las poblaciones autóctonas de los mismos podría explicar la diferencia de enfoque entre la imagen de los países, generalmente negativa, y la de sus correspondientes habitantes, mayoritariamente positiva.

\section{LA SOCIEDAD RECEPTORA}

Las personas entrevistadas por los periódicos describen a la sociedad en la que viven como no prejuiciosa a nivel "racial": hablan de una sociedad española "no racista" o "abierta a la diversidad". España es presentada como un país rico, con el índice de natalidad más bajo de Europa, y el tercero - y más adelante, el segundoen adopciones de niños nacidos en el extranjero. Se menciona su Administración moderna, el hecho de que tenga uno de los porcentajes más bajos de aadopciones fracasadas", y la legislación de AI más abierta del mundo. Aparecen algunas referencias a "los españoles", en las que se alude a su fondo compasivo, su solidaridad y su conciencia sobre lo que ocurre en otros países del mundo.

En lo referente a Cataluña, los periódicos examinados indican que tiene una natalidad inferior a la española, y señalan reiteradamente, con un vocabulario que denota complacencia, su lugar como líder mundial en las AI. También se la cita como "a la vanguardia", "pionera" en medidas de protección a la infancia. Políticos y periodistas describen a la población de Cataluña como poseedora de una gran sensibilidad, una vocación abierta y universal, y altos niveles de solidaridad y civismo. En los comentarios recogidos durante las entrevistas se adjetiva a Cataluña y a los catalanes en el mismo sentido, dibujando una sociedad solidaria, más receptiva y abierta, y con gobiernos que propician las $\mathrm{AI}$, rasgos que la diferenciarían del resto de España. A esto debe agregarse que, mientras que en otros sitios los candidatos a la adopción sopesan la importancia de ser portador de rasgos físicos singularizados antes de adoptar en el extranjero (Ouellette y Méthot 2000: 9; Fréchon y Villeneuve-Gokalp 2004: 66; Berástegui 2003: 239), tanto las personas retratadas en la prensa como los padres y madres entrevistados para esta investigación declararon haber priorizado otros aspectos en el momento de elegir el país donde presentar la solicitud de AI (rapidez del proceso adoptivo, edad de los menores, simplicidad de los trámites, etc.), ya que la alteridad fenotípica no parece ser considerada factor de riesgo para la inclusión del 
menor en la sociedad receptora. Todo esto parece reforzar la idea avanzada más arriba, de que los solicitantes o adoptantes españoles en general, y los catalanes en particular, sostienen que viven en una sociedad abierta a la diversidad, en la que sus hijos no tendrán problemas debido a su apariencia física.

El manejo del lenguaje triunfalista en la prensa acerca de distintos aspectos de las AI pudo haber contribuido a crear una imagen distorsionada del proceso, e inclusive, haber influido en lo que algunos autores llamaron el "efecto moda". En el caso específico de Cataluña, el discurso y las acciones de los sucesivos gobiernos habrían contribuido en gran medida a construir y transmitir ese "orgullo" por ser el territorio en el que más se adopta. Esto también se ve reflejado en su explícita flexibilidad en las emisiones de certificados de idoneidad favorables (Vilaginés Ortet 2007: 119; Brancós Coll 2008: 4-5), señalada a la prensa por altos cargos de distintos gobiernos de la Generalitat de Cataluña, aunque esto no parece ser privativo de la comunidad autónoma. A partir de 2005 - cuando las cifras comenzaron a descender- y hasta 2007, la prensa estudiada minimizaba la importancia de la baja en el número de solicitudes y de AI concretadas. No obstante, a medida que pasan los años son más frecuentes los artículos periodísticos que detallan las "dificultades" con las que se encuentran quienes deciden adoptar en el extranjero. En 2005, tanto las administraciones nacional y autonómica como varios profesionales y funcionarios, comenzaban a expresar sus reservas acerca del creciente número de AI y las posibles consecuencias. El gobierno de Cataluña iba más allá, imponiendo un giro completo en el discurso oficial: de impulsar las AI $-\mathrm{y}$ preferentemente aquellas realizadas a través de una ECAI - se pasaba a fomentar la adopción nacional y el acogimiento. Tal vez la razón de este cambio se encuentre en la necesidad de reorientar a algunos grupos de solicitantes hacia estas dos formas de protección de la infancia, persiguiendo el vaciado paulatino de los centros de menores tutelados por la comunidad autónoma ${ }^{7}$. Para conseguirlo eran necesarias ciertas modificaciones en la legislación, que se completaron con la sanción de la Ley de derechos y oportunidades de la infancia y la adolescencia $^{8}$, además de la ley de matrimonio civil de parejas homosexuales ${ }^{9}$ y la modificación del Código de Familia en Cataluña ${ }^{10}$. No obstante esta clara voluntad, el accionar de los órganos de gobierno no parece ir en el mismo sentido: el porcentaje de CI concedidos no descendió en absoluto. Pero además, en octubre de 2005 la Generalitat anunciaba que, como consecuencia de la aplicación de la Ley de Apoyo a las Familias ${ }^{11}$, los catalanes que adoptaran en el extranjero recibirían una ayuda económica de $2.346 €$, dependiendo de su nivel de ingresos, medida que comenzó a implementarse a partir de 2006, y que seguía siendo aplicada en 2010.

Este estímulo gubernamental de las AI, que en épocas se traduce en triunfalismo, puede ser parte de un proyecto político para una comunidad autónoma con una población envejecida y un índice de fertilidad que está por debajo del de reemplazo

\footnotetext{
${ }^{7}$ España es el único país de la UE con el 75\% de los menores tutelados residiendo en instituciones estatales.

${ }^{8}$ DOGC núm. 5641, de 02-06-2010 - http://www.gencat.cat/diari/5641.

9 BOE núm. 157, Ley 13/2005 - http://www.boe.es/boe/dias/2005/07/02/pdfs/A23632-23634.pdf.

${ }^{10}$ DOGC núm. 4366, de 19-04-2005, p. 9935 - http://www.gencat.cat/diari/4366.

${ }^{11}$ BOE núm. 189, Ley 18/2003, del 4 de julio, de Apoyo a las Familias http://noticias.juridicas.com/ base_datos/CCAA/ca-118-2003.t1.html\#a1.
} 
generacional. En este punto, no puedo dejar de lado la asociación con una reflexión de Dorow (2006: 208) cuando expresa que la AI es "culturalmente poderosa", en términos simbólicos y materiales, ya que "alimenta el mito de unos EE. UU. [léase "una Cataluña" en el marco de este trabajo] que de manera benevolente educa y recibe al mundo". Yngvesson (2010: 96) plantea algo similar para las adopciones en Suecia, cuando propone que las familias que adoptaron menores etíopes "se convirtieron en ensayos de la idea de que, puestos en el entorno - intimo- apropiado, las formas más extremas de diferencia podían ser absorbidas". Esto era particularmente importante en una época en la que se planteaban preguntas acerca de la capacidad y voluntad de Suecia de convertirse en una nación de inmigrantes. Según la autora, las personas adoptadas "encarnan los ideales más altos de la nación sueca de justicia social y solidaridad internacional y resultan por lo tanto, un símbolo de la bondad — parental, nacional- sueca, y de su capacidad para mostrarse como ejemplo para el resto del mundo" (Yngvesson 2010: 120). En el marco de un hipotético proyecto político similar para Cataluña, surgen varios interrogantes que podrían traducirse en objetivos de una futura investigación: ¿Es esto lo que se espera de ellos? ¿Podrá el joven «diferente" - y el adulto en el que se convertirá - transformar no sólo a su familia adoptiva, sino a la sociedad en general y a los términos de pertenencia a ella? ¿Desearán ellos asumir esa responsabilidad?

\section{LOS ADOPTANTES}

Los adoptantes son retratados por la prensa como "aventureros deseosos de ayudar" que "Se lanzan a la adopción" y libran "batallas altruistas" en las que "salvan a los niños necesitados". Ese carácter salvador, valiente, abierto, generoso y progresista, es la otra cara de la imagen de víctima atribuida a los menores susceptibles de adopción, como veremos más adelante. Varios padres y madres también usaron algunos de estos rasgos al auto-describirse, al mismo tiempo que mencionaban el carácter "SOlidario", "comprensivo" o "muy abierto" de sus familias. Los educadores les admiran, y asumen el deseo de $\mathrm{pa} /$ maternidad, que sobreentienden como preexistente a la $\mathrm{AI}$, como una garantía de que serán buenos padres/madres, en coincidencia con lo descripto por otros autores (Mateo 1995: 50-52; Vilaginés Ortet 2007: 20; Mirabent y Ricart 2005: 33).

En otro orden de cosas, la prensa suele mencionar el origen de los adoptantes, llamándolos "familias madrileñas", o "padres catalanes", a menudo en un discurso que crea pares de oposición con el lugar de origen de los niños adoptados o a adoptar, a los que denomina "hijas chinas" $\mathrm{O}$ "niños de fuera", por ejemplo.

Cuando la prensa analizada hace alusión a la situación socio-económica de los candidatos adoptantes, informa de que la mayoría de los solicitantes de AI tienen ingresos superiores a la media de la población general, son propietarios de sus lugares de habitación y cuentan con un trabajo estable. Durante las entrevistas fue posible constatar que la gran mayoría de madres y padres tienen un alto nivel de formación, y que todas las familias, a excepción de una, son propietarias del lugar en el que residen. Si a estos datos se suma el hecho de que muchas de las AI solicitadas por españoles se concretaron en los países en los que los trámites son más caros 
—Europa del Este y China- es posible deducir que para los solicitantes españoles, y entre ellos, los catalanes, el coste de los trámites de adopción no era -al menos hasta 2009, año de realización de las últimas entrevistas- un factor de peso en el momento de la elección del país al que dirigir la solicitud. Esto se confirma porque en las entrevistas no aparece como condicionante entre las razones enumeradas para la elección del país de origen y por la ausencia casi total de alusiones al tema. Así pues, guiándome por la bibliografía (Font Lletjòs 2008; Brancós Coll 2008: 59), los datos publicados en la prensa analizada y los obtenidos a través del análisis de las entrevistas, puedo proponer que la AI es poco accesible para candidatos que no posean una sólida situación económica —ingresos superiores a la media española, propietarios de su vivienda habitual, trabajo estable ${ }^{12}$.

La mayoría de las familias entrevistadas esperan que sus hijos/as, de mayores, sean felices, independientes, buenas personas, etc. Asimismo, varios manifestaron su convicción de poder ver satisfechas sus expectativas de un diploma universitario en sus manos. Se trata de padres/madres de menores o jóvenes que llegaron a Cataluña con tres años de edad o menos. Son menos numerosos los que predicen futuros académicos y profesionales más inciertos; este grupo está generalmente formado por padres y madres de niños que fueron adoptados cuando tenían entre cinco y catorce años, y que habían tenido o estaban teniendo algún tipo de dificultad escolar.

A pesar de no haber sido considerada por los informantes al elegir el país en el que presentar su solicitud de adopción, la diferencia fenotípica entre padres e hijos, y entre hijos y sociedad receptora está presente en la gran mayoría de las $\mathrm{AI}^{13}$. No obstante, los adoptantes suelen señalar ciertas similitudes entre los diversos integrantes de la familia: se mencionan gestos, formas de hablar, e inclusive rasgos físicos. Algunos autores interpretan el hecho de que padres e hijos digan compartir similitudes físicas y comportamentales como una de las estrategias de "emparentamiento" o "kinning" (Howell 2006). Otros piensan que "lo que está realmente en juego es la creación de lazos relacionales para compensar de manera imaginaria la ausencia de lazos de sangre", entendiendo que, para la mayoría de los adoptantes, la filiación adoptiva es una opción "de segunda" (Ouellette y Belleau 1999: 83). Pero mientras que los padres y madres buscan rasgos comunes, algunos de los menores adoptados cuestionan la relación paterno-filial basándose en esas mismas diferencias fenotípicas. Esto parece superarse una vez que comprenden plenamente las implicaciones de la adopción. La controversia vuelve a aparecer en el entorno social de las familias entrevistadas porque, debido a las diferencias fenotípicas existentes entre ellos, "la mayoría de los menores adoptados en el extranjero no pueden ser confundidos como siendo hijos biológicos de sus padres" (Howell y Marre 2009: 213); como no se asemejan, no pueden ser parientes "verdaderos".

\footnotetext{
${ }^{12}$ Aunque esto podría deberse a una auto-selección previa, basada en la imagen que las familias pertenecientes a clases sociales menos favorecidas tiene de la AI (Halifax y VilleneuveGokalp 2005: 3).

${ }^{13}$ En el mismo sentido, en su análisis sobre los seguimientos obligatorios llevados a cabo con las familias adoptivas de la Comunidad de Madrid, Ana Berástegui (2010) constató que el 82\% de ellas no había hablado nunca con su hijo/a acerca de sus diferencias fenotípicas.
} 


\section{LAS PERSONAS ADOPTADAS}

\subsection{Reflejos de "auto-identificación"}

Los niños y jóvenes adoptados en el extranjero, aquellos que inmigraron con sus familias, los hijos e hijas de inmigrantes nacidos en Cataluña y, muy probablemente, los hijos e hijas de parejas mixtas -siempre que sean portadores de rasgos fenotípicos minoritarios- tienen en común una pregunta que les persigue durante toda su vida: "¿De dónde eres?" Probablemente muchos hijos e hijas de las familias entrevistadas para esta investigación, portadores de fenotipos diferenciales, ya habían oído esa pregunta y percibido miradas externas singularizadas. Esto explicaría que la abrumadora mayoría de las respuestas dadas por padres, madres y educadores ante la pregunta acerca de cómo se describirían — a su entender - sus hijos y alumnos, hacía alusión a sus "diferencias". Diferencias que pueden tener connotaciones variadas, pero que en buena parte de los testimonios hacen alusión a ciertos rasgos físicos, entre los cuales el color de piel "no blanco" y el cabello muy rizado son retenidos muy frecuentemente como "problemáticos". Algunas personas mencionaron que su hijo o alumno "se ve guapo" o "se gusta"; otros hablaron de un cambio de actitud: durante un tiempo "no se gustaban", y vivían la diferencia como una fuente de problemas y conflictos, pero más adelante esa diferencia pasó a ser una ventaja. Aunque la gran mayoría de los informantes describió opiniones bastante negativas de los menores y jóvenes sobre su aspecto, agregando que casi todos los chicos manifestaron de alguna manera y en algún momento que hubieran preferido ser "iguales" a su entorno.

El hecho de ser adoptado no aparece como un rasgo suficientemente importante para ser incluido en la "auto-identificación" — siempre según los testimonios de los adultos-, coincidiendo con lo señalado por Howell (2004: 215). No obstante, como plantean Mirabent y Ricart (2005: 146), el fenotipo diferente estaría estrechamente ligado con el hecho adoptivo: "ser de etnia diferente no es una cosa inocua, porque ser diferente remite al hecho que uno ha llegado a la familia de una manera diferente, con todo lo que ello comporta". O sea, "el hecho de haber nacido de unos progenitores que no son los padres, la historia de un abandono" (Grau y Mora 2004: 23). Por lo tanto, el otro aspecto conflictivo de ser portador de alteridad fenotípica es su carácter diferenciador del resto de la familia, que se suma a la singularidad con respecto a la sociedad receptora mayoritaria, fuente de situaciones de discriminación vividas por jóvenes y menores.

\subsection{La identificación externa y las estrategias derivadas}

Partiendo del contenido de la prensa, aunque casi ausente en las entrevistas, se observa que la percepción corriente es que hay "millones de niños pobres que esperan una adopción". Esta visión de "abundancia de niños a la espera" confunde "niños pobres" con "niños adoptables", como si fueran sinónimos, y además atribuye a los menores un rol totalmente pasivo. El lenguaje usado deshumaniza completamente a los niños, como cuando se habla, por ejemplo, de niñas y niños "importados", "dados" en adopción, "ofrecidos a extranjeros" o "cedidos". Son considerados "objetos" de 
adopción, "posesiones" de sus padres y madres — aspecto también mencionado por Panchón y Heras (2009: 49) — sin voz ni voto, cosificados y, a veces, intercambiables, haciendo aparecer la "sombra de la mercantilización sobre el niño" (Anagnost 2000: 407). Esa "Cosificación" de los niños se combina a menudo con el uso del lenguaje comercial ya mencionado.

La prensa analizada suele describirlos como "víctimas sin familia", y sin posibilidades de supervivencia fuera de la AI. A pesar de haber considerado a la AI como el "último recurso" para formar o agrandar sus familias, algunos informantes la presentan como la única opción de vida para los niños adoptables, en la que los padres y madres encarnarían a los "salvadores" y los niños serían las "víctimas" rescatadas de unas condiciones de vida miserables y un futuro incierto. Serían "supervivientes" que tendrían ante sí la oportunidad de convertirse en miembros de un grupo social "privilegiado", protagonizando no sólo un cambio de país y contexto cultural, sino también de clase social.

Estos hijos e hijas tan deseados son considerados "anormales", frente a la "normalidad" representada por los "niños españoles". Esa "anormalidad" va asociada con una historia previa que puede o no incluir orfandad, abandono, malos tratos y carencias, pero que se relaciona de manera ineludible con su origen en un país lejano, rasgo íntimamente asociado con sus características fenotípicas "distintas". Frecuentemente se sugiere que el hecho de haber nacido en otro país implica la existencia de una diferencia cultural de la que el niño o la niña son portadores, como algo intrínseco a él o ella. La diferencia fenotípica se usa entonces como un indicador de diferencia cultural, donde la cultura es percibida en cierta medida como "heredada" de una manera casi "natural". Esto se manifiesta en algunas entrevistas cuando, por ejemplo, la madre de una niña nacida en Nepal y llegada a Cataluña con menos de dos años dice que su hija es "discreta y callada, como buena nepalí"; o cuando el padre de una niña originaria de Rusia cuenta que a su hija le gustan los colores vivos porque a la gente de su país de origen le gustan. Charro y Jociles (2008: 116) detectaron algo similar en los mensajes de los técnicos de las instituciones intermedias involucradas en la AI, cuando presentan a la cultura de origen "como un elemento cuya impronta en la vida de los niños, por muy temprana que haya sido la edad en que han sido adoptados, se presenta como ineludible».

Pero la alteridad fenotípica asociada a la diferencia cultural intrínseca se relaciona además con una no-pertenencia a la sociedad receptora. Así, en todas las fuentes explotadas es muy redundante la descripción de estos niños y jóvenes como siendo "de fuera", y atribuyéndoseles un país distinto a éste: su país de origen. Se establece así una clara relación entre el cuerpo biológico y la pertenencia nacional, en lo que parece ser una concepción de nación como comunidad "racializada", con un sentimiento de ascendencia común. Como propone Diana Marre:

Esta incompatibilidad percibida entre ser español y ser físicamente "no europeo" es parte de la creencia de que los padres adoptivos son "étnicamente" homogéneos - todos "blancos" o "Caucásicos" - a pesar de los siglos de intercambio sexual y colonial entre España, África del Norte y América Latina (Marre 2007: 81).

Lo mismo fue observado en una sociedad tan heterogénea como la canadiense, donde las personas adoptadas en el extranjero "tienen la ciudadanía canadiense, pero 
su origen les impide disfrutarla sin obstáculos, como los [otros] inmigrantes que deben siempre confirmar la legitimidad de su estatus o la validez de sus documentos de identidad" (Ouellette y Saint-Pierre 2008: 88).

Distintos autores (Weil 1984; Lovelock 2000; Selman 2002; Martínez Roig 2004; Brancós Coll 2008; Khabibullina 2008) describen a los menores adoptados en el extranjero como inmigrantes. A pesar de coincidir más particularmente con Weil (1984: 277), cuando plantea que los menores adoptados en el extranjero pertenecen a una categoría de "migrantes forzados", ya que son desplazados de un país a otro sin que su opinión sobre el tema sea tenida en cuenta, de las entrevistas se desprende que no son percibidos como "inmigrantes". Lo mismo fue señalado por varios autores a partir de sus trabajos (Volkman 2003: 29; Marre y Bestard 2004: 42; Howell 2004:210; Dorow 2006: 210; Howell y Marre 2006: 311; Howell y Melhuus 2007: 57; Khabibullina 2008; Yngvesson 2010: 98). Entre los educadores entrevistados, esta diferencia se hace evidente cuando los comparan con los hijos e hijas de inmigrantes, a quienes sí consideran "inmigrantes". La diferencia principal entre ambos grupos de niños radicaría en la socialización: los menores adoptados habrían sido educados en un entorno cultural local, por personas portadoras de rasgos culturales considerados catalanes y pertenecientes a familias "de aquí, mientras que los hijos e hijas de inmigrantes seguirían hablando la lengua de sus progenitores - también considerada "su" lenguay habrían sido educados en un entorno cultural "otro" por sus familias "de fuera". Hay, sin embargo, ciertas similitudes señaladas entre ambos grupos: todos son niños considerados "de otro país", portadores de rasgos físicos que los identifican como tales. Una educadora expresó que una niña nacida y adoptada en Etiopía "parecía una niña totalmente de aquí en poquitos meses"; la madre de una niña nacida en Nepal dijo que todos los niños y niñas adoptados en otros países, "Son más maduros que los de aquí"; dos niños nacidos en Brasil tendrían, en un caso, el "típico temperamento brasileño" y sería "lento, humilde y sincero" como "la gente de allí, en el otro. Ninguno de estos menores tenía más de tres años al llegar a Cataluña. Por todo ello, y contrariamente a lo observado por Howell (2004) en Noruega, los niños y jóvenes adoptados no son considerados "catalanes", aunque sí "menos extranjeros" que los hijos de inmigrantes, por lo que resultan, en definitiva, "como si fueran catalanes", con sus rasgos fenotípicos en la base de esta pertenencia parcial, por lo que sería necesario "Cerrar los ojos" para que sean "de aquí". Esto coincide completamente con lo que Indigo Williams (2003: 42) describe con respecto a los australianos nacidos y adoptados en Vietnam, o lo que Barbara Yngvesson (2010:101) y Tobias Hübinette (2010: 6) señalan para los adultos adoptados transnacionalmente en Suecia.

Que estos menores hayan nacido en otro país y hayan sido engendrados por otra gente, portadora de otra cultura, da origen a ciertas diferencias, reales o imaginadas, a nivel de las representaciones. Esas diferencias resultan en el uso de ciertas estrategias particulares por parte de las familias entrevistadas. Estas últimas llevan a cabo acciones cuyo objetivo es introducir a sus hijos a la "cultura catalana" o a lo que ellos entienden por eso, por lo que varios de esos niños participan de grupos que recrean tradiciones de Cataluña: forman parte de colles de castellers, o participan de esbarts dansaires y esplais. Lo sorprendente es que en las familias con hijos biológicos y adoptivos, estas prácticas sólo se reservan a los segundos. A excepción de una, todas las familias hablan catalán desde el principio con sus hijos, aunque estos pro- 
vengan de países de América Latina, y ya hablen castellano. Resulta apropiado recordar, por un lado, la importancia que la lengua tiene entre los catalanes como marcador identitario nacional, y por otro, que entre 1998 y 2009 los catalanes adoptaron, en términos proporcionales, menos niños y niñas provenientes de América Latina —castellano-hablantes, si ya manejaban la lengua - que los españoles en general (INE; $I C A A)^{14}$. Pero además, el dominio del catalán es considerado por los entrevistados como uno de los principales indicadores de "integración" o "adaptación" de sus hijos y alumnos. Estas evidencias permiten sugerir que tal vez las familias y personas adoptantes en Cataluña prefieren optar por países de origen en los que la población hable idiomas que no "entorpezcan" la catalanización de sus hijos e hijas, esto es, no castellano-hablantes.

Curiosamente, al estudiar los relatos de adopción de las familias entrevistadas, aparece una correlación negativa entre la edad creciente de los niños a su llegada a la comunidad autónoma, y las estrategias de catalanización —enculturación- puestas en práctica por la familia: las acciones que estimulan la catalanización disminuyen cuanto mayor es el niño en el momento de su adopción.

En otro orden de cosas, algunos autores (Mateo 1995: 56; Mirabent y Ricart 2005: 146-148; Sallessi 2008: 10; Melina 2001: 133), las asociaciones de familias adoptantes, y otras instituciones implicadas en el proceso de AI (ISS-SSI 2004) coinciden en recomendar a las familias adoptivas el "respeto" y la "Conservación de la cultura del país origen" de sus hijos adoptivos. El 74\% de los hijos e hijas de las familias entrevistadas tenía menos de tres años cuando llegaron a Cataluña. La corta edad de esta población en el momento de su llegada a la comunidad autónoma plantea ciertas preguntas: ¿es posible en estos casos hablar de "conservación" de una cultura diferente a la del sitio en que estos niños y niñas crecieron y viven en la actualidad, cuando el término presupone que esos menores son portadores de una cultura "Otra"? ¿Por qué sería deseable hacerles partícipes de aspectos de una cultura con la que han tenido muy poco contacto? Si se defendiera esta necesidad, ¿en qué medida las familias adoptantes tienen la capacidad de transmitir una cultura no propia a sus hijos e hijas, a pesar de no ser portadores de ella? Autores como Tizard y Phoenix (1994: 95) niegan que una persona portadora de una cultura dada tenga la capacidad de transmitir otra cultura de manera fehaciente. Además de las razones estipuladas en los tratados internacionales, los autores partidarios de esta estrategia — principalmente provenientes de la psicología - se basan en el significado otorgado a la historia temprana de los adoptados antes de su llegada a España. Suelen asentar esta necesidad en la idea de que los mensajes positivos sobre la cultura del país de origen refuerzan la autoestima de los menores, propiciando así la formación de una "identidad positiva". Esta es también la explicación más frecuente de los padres, madres, educadores y profesionales de la AI entrevistados que hicieron alguna alusión al tema. Lo más corriente es buscar material audio-visual o escrito acerca del país de origen, y compar-

\footnotetext{
${ }_{14}$ Datos del INE: http://www.ine.es/jaxi/tabla.do?type=pcaxis\&path=/t25/a072/a02/10/ \&file $=$ c70004.px

Datos del ICAA: http://www20.gencat.cat/portal/site/bsf/menuitem.5d1bf6d61dd9162a172a63a 7b0c0e1a0/?vgnextoid=ee3bfb6efe254210VgnVCM1000008d0c1e0aRCRD\&vgnextchannel= ee3bfb6efe254210VgnVCM1000008d0c1e0aRCRD\&vgnextfmt=default\&newLang=ca_ES
} 
tirlo con los menores, aunque varias familias comentaron además haber traído algunos objetos como música, libros, juguetes, vestimenta típica o recetas de cocina del viaje de adopción, que incorporaron a la cotidianeidad familiar. Ouellette y Méthot (2000: 135) consideran que el espectro de selección en el que operan los adoptantes es relativamente restringido, reduciéndose a los «aspectos folklóricos de la cultura o de los rasgos típicos del modo de vida tal y como son perceptibles por los extranjeros de paso". Otras familias optan por exaltar las cualidades de personajes públicos (futbolistas, actores, etc.) que comparten rasgos físicos u orígenes con los menores en cuestión, sin que hayan sido mencionadas personas del entorno social cotidiano de la familia. En el mismo sentido, Volkman (2005: 92) critica a algunas familias estadounidenses con hijos/as adoptados en China que "se obsesionan con China y su cultura, mientras que ignoran completamente a la cultura chino-americana que tienen a la vuelta de la esquina". Las reuniones con otras familias adoptantes en el mismo país, los encuentros organizados por las asociaciones, o los viajes turísticos al país de origen de sus hijos también fueron incluidos como estrategias para "conservar la cultura del país de origen". Es cierto que los viajes pueden aportar cierta información al respecto, aunque se limite a una "visión turística". Pero el contacto con otros niños del mismo origen que viven con sus familias españolas desde muy temprana edad no puede aportar mucho a la "conservación de la cultura del país de origen", a menos que entendamos que la apariencia "diferente" se asocia inexorablemente con "diferencia cultural".

Puede parecer paradójico, pero esos esfuerzos por "conservar la cultura del país de origen" son llevados a cabo por muchas familias que, simultáneamente, ponen en práctica acciones para catalanizar a sus hijos. Estas dos prácticas no parecen contrapuestas, sino que conviven en las dinámicas familiares. Quizá se deba a que las familias entrevistadas encuentran cierta lógica en el discurso de los profesionales de la adopción cuando defienden la necesidad de encontrar un equilibrio entre el respeto a los orígenes y la integración del menor a su contexto familiar y social actual.

Aunque el conjunto mayoritario de adoptantes manifestó seguir el consejo de los profesionales sobre el "respeto y conservación de la cultura del país de origen" de sus hijos limitándose a compartir con ellos ciertos objetos recolectados en el viaje de adopción, dos grupos se desvían de esta conducta: los adoptantes en Etiopía —quienes generalmente hacen esfuerzos más importantes para "conservar los orígenes" de sus hijos e hijas-, y algunas familias - principalmente adoptantes en América Latina- que no hicieron ninguna alusión a la necesidad de "mantener vivos los orígenes". Quienes más énfasis ponen en la conservación de la cultura del país de origen de sus hijos e hijas son las familias de niños de piel negra, generalmente originarios del África subsahariana. Puede que esas personas sientan una necesidad más apremiante de enseñar a sus hijos una imagen diferente a la que los medios suelen transmitir sobre sus países de origen y sus poblaciones. Las personas de piel negra son percibidas como "las más lejanas", o perteneciendo al grupo de "los más diferentes" (Cea y Valles 2009: 165) en una sociedad receptora donde las "diferencias" —físicas y/o "culturales" - son consideradas potenciales fuentes de conflictos, por lo que son quienes viven con más frecuencia situaciones discriminatorias de mayor o menor gravedad (Marre 2007: 84). En este sentido, esta actitud podría representar una estrategia de la familia para proteger al menor contra la discriminación. El otro grupo, for- 
mado principalmente por adoptantes en América Latina, no habló de iniciativas para con la cultura del país de origen de sus hijos e hijas. Es conveniente mencionar que en las entrevistas los adoptantes señalaron a los países de América Latina —especialmente a Colombia - como los "más cercanos".

Por otro lado, la prensa analizada describe a los solicitantes españoles como "cercanos culturalmente" a los países de "Europa del Este", aspecto usado para explicar el gran número de solicitudes presentadas en esos países. Tanto en uno como en otro caso, ¿es la "cercanía cultural," o la fenotípica la que se señala? A mi entender, podríamos estar aquí ante un indicio de la asimilación entre fenotipo y cultura: los niños portadores de rasgos físicos similares a los de la mayoría de la sociedad receptora serían percibidos como portadores de otra cultura, pero más cercana a la española y/o catalana. Esta idea queda reforzada si se tiene en cuenta que las familias que adoptan en los países de "Europa del Este" parecen estar menos interesadas en la "cultura" del país de origen de sus hijos, que consideran muy similar a la propia (Marre 2007: 83), y que las familias entrevistadas que no parecen sentir la necesidad de "preservar la cultura del país origen de sus hijos" adoptaron mayoritariamente en Colombia. Además, es el mismo grupo que dijo no haber vivido nunca situaciones de discriminación, argumentando que se trata de adopciones "no visibles". Sobre ese punto debo decir que, a diferencia de lo recogido en el trabajo de Ana Berástegui (2005: 330), el 64\% (16/25) de las familias entrevistadas para este estudio relató al menos una situación discriminatoria vivida por sus hijos, generalmente minimizándola. Las proveniencias de los menores son diversas, aunque predominan los de África y los de países andinos de América Latina; los adoptantes en Asia estaban más divididos en este punto. Si a esto se suma el hecho que los menores de pieles oscuras son quienes han vivido con más frecuencia situaciones discriminatorias, debe concluirse entonces que, según las opiniones de los entrevistados, la similitud o diferencia fenotípica con la familia y con la sociedad receptora mayoritaria estarían condicionando las reacciones del entorno, protegiendo en ciertos casos, y explicando en otros, las agresiones racistas y xenófobas. Por otro lado, todas las familias que negaron haber sufrido algún tipo de discriminación lo explicaban en términos de apariencia física: los menores no se diferencian físicamente de ellos ni de la población local mayoritaria. Esta ausencia de discriminación puede asociarse con una de las conclusiones de este trabajo: a más diferencia fenotípica, mayores posibilidades de vivir situaciones de discriminación, en una sociedad en la que la gente de piel no blanca aparece como la más diferente. Pero entonces, ¿por qué los niños negros son percibidos como siendo "más diferentes" que las niñas originarias de China, por ejemplo? En Cataluña, como en todos lados, la gente "de fuera" no constituye una categoría homogénea: algunos son percibidos como menos "de fuera" que otros, más como "nosotros". No es necesariamente el fenotipo sensu stricto el que está a la base de esta mirada, sino la asociación directa que la sociedad en general hace entre un fenotipo y el estereotipo predominante sobre los supuestos lugares de origen de las personas presentes en esta sociedad, como sucede en otros sitios (Morrier 1995; Ouellette y Belleau 1999: 69; Yngvesson 2010: 126). Tal como propone Peter Wade:

The analysis of 'race' is not reducible to an objectivist vision undertaken by neutral observers, but takes place from, and can be deconstructed from, a body of knowledge situated in a specifically Western history (Wade 2002: 4). 
Siguiendo a Ben Campbell (2007: 172), sostengo que esta codificación de las características fenotípicas resiste como un "modelo organizador más allá de la genética, moldeando las percepciones de las caras de la desigualdad en la sociedad actual". Si recordamos la reflexión de Sterett (2002) cuando plantea la estrecha relación existente entre el tratamiento que las naciones hacen del tema de la raza en la adopción y en la ciudadanía, ya que "la familia es el escenario más íntimo de producción de ciudadanos", es posible aseverar que para que las personas adoptadas en el extranjero puedan desarrollarse como miembros plenos de esta sociedad, será necesario trabajar los estereotipos y prejuicios que la población local maneja acerca de las poblaciones de los países del llamado "Tercer Mundo" de donde son originarios. Mientras la sociedad local mire a todos aquellos a quienes considera "de fuera" a través de los prejuicios y estereotipos existentes hoy, los menores y jóvenes adoptados en el extranjero, portadores de fenotipos diferenciales "racializados", no serán incluidos como ciudadanos con plenos derechos, al igual que cualquier otra persona que comparta con ellos esta característica.

En sus relatos, la gran mayoría de los adultos entrevistados minimizan las agresiones racistas y xenófobas. Lo hacen diciendo que "no sucede muy a menudo", o que "los niños son crueles", o aún "se meten con quien es negro, como con quien es gordo, como con quien lleva gafas". Suelen aconsejar a los menores ignorar las agresiones, alejarse de los agresores, o responder con otras agresiones. Pero, por otro lado, esos mismos adultos manifiestan temor por el futuro de sus hijos y alumnos en lo que respecta a su posición de "minoría" en una sociedad que puede discriminarlos, lo que los lleva a usar un lenguaje y a tomar ciertas actitudes "defensivas". Así, muchos hablan de "armar" a los menores para que puedan "defenderse". Varios de los educadores y profesionales entrevistados expresaron que es posible que algunos adultos no estén respondiendo de manera satisfactoria a las quejas de los menores en este aspecto, porque no están preparados para ello, ya que nunca han vivido situaciones similares ni han sido suficientemente formados para hacerlo. En el caso de los educadores, Deusdad (2009: 149) comprobó esta carencia y señaló la necesidad de formaciones para adquirir "estrategias y recursos didácticos" para saber cómo tratar "actitudes racistas, xenófobas y de menosprecio".

Esa mirada discriminatoria sobre sus hijos e hijas podría estar en el origen de otra estrategia presente en los discursos de varias familias: la "ceguera a la diferencia" (Hübinette y Tigervall 2006: 6) o "rechazo a las diferencias" (Berástegui y Gómez-Bengoechea 2007: 30). Se manifiesta en frases como "iYo ya no me doy cuenta que es negro!" o "Yo ya la veo como una niña normal". Si para la sociedad circundante, ciertos rasgos diferenciales de una persona son percibidos como fuente potencial de exclusión, la "ceguera" a esa diferencia permitiría a las familias — desde su punto de vista exclusivo- incluir a sus hijos e hijas en la sociedad en la que viven. Sin embargo, allí está la mirada del entorno, cuestionándolo, con preguntas como "¿De dónde es tu hijo?", o asombrándose porque las niñas chinas hablan catalán. Ante la ineficacia de la estrategia de negación de la diferencia, algunos padres y madres optan por la estrategia opuesta, es decir, la "insistencia en las diferencias" (Berástegui y Gómez-Bengoechea 2007: 31). Esos adultos repiten a sus hijos, por ejemplo, que "es un nene de chocolate", o que es "una niña china" con los riesgos que esto implica, ya que podría poner en cuestión la pertenencia del menor a la familia y al entorno social de adopción. 
En cuanto al hecho de haber sido adoptados, los adultos intentan "normalizar" la situación, presentando a la AI como una realidad numerosa, con un vocabulario específico. Esta estrategia parecería haber dado sus frutos, ya que el hecho adoptivo es raramente usado como motivo de discriminación. Sin embargo, algunos entrevistados señalaron que, en las escuelas, suele ser usado como "explicación" ante cualquier "dificultad" experimentada por el menor.

\subsection{Reflejos de "auto-identificación" vs. Identificación externa}

De lo expuesto resulta claro que coexisten al menos dos percepciones diferentes en lo que concierne a la pertenencia local o nacional de las personas adoptadas en el extranjero: mientras que la mayoría de los menores y jóvenes reivindicaría — según sus padres, madres y educadores - su pertenencia exclusiva a la sociedad receptora o una doble pertenencia, la prensa habla de ellos como siendo "de fuera". Estudios anteriores (Brodzinsky 1990; Triseliotis 1991; Cederblad et al. 1999; Kirton 2000; Sætersdal y Dalen 2000; Howell 2004; Hübinette 2004; Mirabent y Ricart 2005; Yngvesson 2007, 2010) mencionan la posibilidad de una contradicción entre la autoidentificación y la identificación externa de las personas adoptadas internacionalmente con fenotipos diferentes a los de la mayoría de la población de la sociedad en la que viven, por lo que uno de los objetivos de esta investigación la consideraba. Pero además, lo que el trabajo pone en evidencia es la presencia de otro conflicto que se agrega al anterior: el existente entre el discurso de los menores y jóvenes adoptados, y el de su entorno más cercano, formado por padres, madres, educadores, y en algunos casos, pares.

Cuando padres, madres y educadores reflexionaron acerca de las pertenencias nacionales reivindicadas por sus hijos, hijas y alumnos, aparecieron tres grupos de respuestas: un primer grupo muy minoritario que dice pertenecer al país de origen; y - mucho más representados - los grupos de aquellos que manifiestan sentir una doble pertenencia con dos sub-categorías: "de aquí, pero nacido/a allá" o "de allá, pero ahora de aquí", y de quienes defienden su pertenencia a la sociedad en la que viven actualmente. Al comparar estas respuestas con lo observado por Brottveit (1999) en Noruega y Morrier (1995) en Canadá, se comprueba que el modelo difiere en que aquí no aparecen personas que reivindican una pertenencia "cosmopolita" o "internacional", mientras que sí aparecen quienes reivindican una pertenencia exclusiva a la sociedad de su país de origen. Esta diferencia podría deberse al tamaño de la muestra, o al hecho de que en este caso entrevisté a los adultos del entorno cercano de las personas adoptadas, mientras que los otros dos estudios incluyen entrevistas a las personas adoptadas. Examinando las opiniones personales de los adultos acerca del mismo tema, se constata que los tres grupos construidos reaparecen, pero con una pequeña diferencia: los adultos pondrían el énfasis en el aspecto extranjero de la doble pertenencia, mientras que los niños y jóvenes darían más peso a su pertenencia a la sociedad catalana o local. Al complementar estas construcciones con el discurso de pertenencia reconstruido transversalmente, a partir de opiniones dadas en diversos momentos de las entrevistas, la distancia de las respuestas se hace más evidente: muchos menores que dicen sentirse catalanes, o de su ciudad o pueblo, tienen en su 
entorno más cercano a algunos adultos que condicionan esa pertenencia, como una madre que describe a su hija como siendo "muy china", u otra que dice que la suya es "de Reus, pero nacida en India", por ejemplo. Esto es exactamente lo contrario a lo hallado por Westhues y Cohen (1997) en Canadá. Vemos así que inclusive entre las familias y educadores hay quienes los consideran "de fuera". La contradicción más frecuente aparece entre los que dicen sentirse catalanes, o de su ciudad o pueblo, y los adultos de su entorno más cercano que "matizan" esa pertenencia, agregando que nacieron en otro lugar, atribuyéndoles otro país como "su país", u otra lengua como "su lengua".

Las identificaciones externas construidas acerca de estos menores y jóvenes les recuerdan de manera constante su origen extranjero y su alteridad fenotípica, lo cual entra en contradicción con la "auto-identificación" de la que son portadores. La mayoría de ellos se "auto-identifica" como perteneciendo a la sociedad local, pero esa misma sociedad no les considera como parte de sí, y actúa en consecuencia. Poco importa la edad del menor a su llegada a Cataluña, el tiempo transcurrido desde entonces, su estatus legal de ciudadano español o su actitud hacia la "cultura" de su lugar de origen. En la mirada de la sociedad receptora y del entorno cercano de los niños y jóvenes adoptados en el extranjero, su apariencia física —asociada con su lugar de nacimiento- señala su alteridad cultural y nacional. Sostengo que, por el hecho de ser portadores de un fenotipo distinto al predominante en la sociedad receptora, estos niños serán considerados como siendo "de fuera" de manera inmutable, sin importar los esfuerzos de catalanización —enculturación- o inclusión que ellos y sus familias pongan en práctica, mientras no cambie el estereotipo que la sociedad receptora tiene de sí misma.

En un futuro próximo, cuando las personas adoptadas en el extranjero involucradas en este trabajo se hayan convertido en jóvenes adultos, será interesante recoger sus opiniones, para contrastarlas con las conclusiones a las que llega esta investigación, y descubrir así las opciones que hayan hecho con respecto a su identificación, explorar las estrategias que construyan para resolver el conflicto existente entre su "autopercepción" y las identificaciones externas, si es que perdura y lo viven como tal, y discernir en qué medida perciben $-\mathrm{O}$ no- y asumen - $\mathrm{O}$ no- la tarea de "transformar" a su entorno que algunos parecen asignarles.

\section{BIBLIOGRAFÍA CITADA}

Anagnost, A. 2000. "Scenes of misrecognition: maternal citizenship in the age of transnational adoption". Positions: East Asia cultures critique 8 (2): 389-421.

Belleau, H. 2000. "L'usage des photographies de famille", en Fine, A. y Neirinck, C. (eds.), Parents de sang, parents adoptifs. Approches juridiques et anthropologiques de l'adoption: 311-323. París: Maison des Sciences de l'Homme.

Berástegui Pedro-Viejo, A. 2003. "Adopción intercultural: diferencias étnico-culturales en el seno de la familia", en Borobio, D. (coord.), Familia e interculturalidad: 229-251. Salamanca: Instituto superior de ciencias de la familia.

Berástegui-Pedro Viejo, A. 2005. La adaptación familiar en adopción internacional: una muestra de adoptados mayores de tres años en la Comunidad de Madrid. Madrid: CES. 
Berástegui-Pedro Viejo, A. 2010. "La integración familiar y social de los menores adoptados internacionalmente: seguimiento postadoptivo en la Comunidad de Madrid". Comunicación en las Jornadas La integración de la adopción internacional, 7-8 de mayo de 2010, Barcelona: CIIMU.

Berástegui Pedro-Viejo, A y Gómez-Bengoechea, B. 2007. Esta es tu historia. Identidad y comunicación sobre los orígenes en la adopción. Familia y sociedad 1. Madrid: Universidad Pontificia Comillas.

Brancós Coll, I. 2008. L'adopció internacional a Catalunya: un nou fenomen demogràfic? Tesis doctoral. Barcelona: Universidad Autónoma de Barcelona.

Brodzinsky, D. 1987. "Adjustment to adoption: a psychosocial perspective". Clinical Psychology Review 7 (1): $25-47$.

Brodzinsky, D. 1990. The Psychology of adoption. Oxford: Oxford University Press.

Brottveit, A. 1999. 'I didn't want to look different'- identity development, external categorisation and ethnic identity of adoptees form Colombia and Korea. Oslo: Norwegian Lutheran Hospital College Center.

Campbell, B. 2007. "Media storylines of cultural hybrid persons and nation", en Wade, P. (ed.), Race, ethnicity and nation. Perspectives from kinship and genetics: 169-186. Nueva York: Berghan Books.

Cea d'Ancona M A. y Valles Martínez, M. S. 2009. Evolución del racismo y la xenofobia en España. Observatorio español sobre racismo y xenofobia. Madrid: Ministerio de Trabajo e Inmigración.

Cederblad, M., Höök, B.; Irhammar, M. y Mercke, A. M. 1999. "Mental health in international adoptees as teenagers and young adults. An epidemiological study". Journal of Child Psychology and Psychiatry 40: 1239-1248.

Charro, C. y Jociles, M. I. 2008. "La construcción de los roles paternos en los procesos de adopción internacional: el papel de las instituciones intermedias". Política y Sociedad 45 (2): 105-130.

Constable, N. 2009. "The commodification of intimacy: marriage, sex, and reproductive labor". The Annual Review of Anthropology 38: 49-64.

Dalen, M. 2001 The State of knowledge of foreign adoption.

http://www.comeunity.com/adoption/adopt/research.html Consultado 25-4-2008

Deusdad Ayala, B. 2009. Immigrants a les escoles. Lérida: Pagès Editors.

Dorow, S. 2006. Transnational Adoption: a cultural economy of race, gender and kinship. Nueva York: New York University Press.

Font Lletjòs, E. 2008 "Perfil de les famílies adoptants a Catalunya". Infància 16. Barcelona: ICAA.

Fréchon, I. y Villeneuve-Gokalp, C. 2004. Étude sur l'adoption. Document de travail. París: INED.

Grau, E. y Mora, R. 2004. "¿Cuándo escolarizar a un niño adoptado?". Nihao 6: 22-24.

http://www.afac.info/nihao-la-revista/conoce-la-revista.html Consultado 14-4-2011.

Grau Rebollo, J. 2004. "Parentesco y adopción. Adoptio imitatur naturam. ¿Nature vs. Nurture?" Quaderns-e, Institut Català d'Antropologia 03/2004a.

http://www.antropologia.cat/quaderns_e Consultado 22-9-2008.

Grau Rebollo, J. 2011. "Parentesco, adopción y crianza. Elaboraciones culturales de la adopción internacional y la circulación de niños". Revista de Antropología Social 20: 31-54.

Grotevant, H. 1997. "Coming to terms with adoption: the construction of identity from adolescence to adulthood". Adoption Quarterly 1: 3-27.

Halifax, J. y Villeneuve-Gokalp, C. 2005. "Adoption in France: who are the adopted children and who are the adopters". Population E Societies 417: 1-4.

Howell, S. 2004. "¿Quién soy yo, entonces? Perspectivas de los adoptados transnacionales acerca de la identidad y la etnia", en Bestard, J.y Marre, D. (eds.), La Adopción y el acogimiento: Presente y perspectivas: 197-221 Barcelona: Universidad de Barcelona.

Howell, S. 2006. The Kinning of foreigners. Transnational adoption in a global perspective. Nueva York: Berghahn Books.

Howell, S. 2009. "Adoption of the unrelated child: some challenges to the anthropological study of kingship". Annual Review of Anthropology 38: 149-166.

Howell, S. y Marre, D. 2006. "To Kin a transnationally adopted child in Norway and Spain: The achievement of resemblances and belonging". Ethnos 71 (3): 293-316. http://dx.doi.org/10.1080/ 00141840600902679 Consultado 17-6-2007.

Howell, S. y Marre, D. 2009. "Discours sur la destinée et adoption internationale", en Porqueres, E. (ed.), Défis contemporains de la parenté: 197-222. París: Éditions EHESS. 
Howell, S. y Melhuus, M. 2007. "Race, biology and culture in contemporary Norway", en Wade, P. (ed.), Race, ethnicity and nation. Perspectives from kinship and genetics: 53-71. Nueva York: Berghan Books.

Hübinette, T. 2004. A Critique of Intercountry adoption. http://www.transracialabductees.org

Consultado 3-2-2008.

Hübinette, T. 2010. "Reflexiones sobre ser y convertirse en un adulto adoptado transnacionalmente en Suecia". Newsletter AFIN 18:2-6. http://www.afin.org.es/ Consultado 12-9-2010.

Hübinette. T. y Tigervall, C. 2006. "Contested adoption narratives in a Swedish setting". 2nd International Conference on Adoption Research. Norwich: University of East Anglia. http:// www.icar2.org.uk/ Consultado 19-6-2010.

Institut Català de l'Acolliment $i$ de l'Adopció (ICAA). Memorias anuales. http://www20.gencat.cat/ portal/site/bsf/menuitem.5d1bf6d61dd9162a172a63a 7b0c0e1a0/?vgnextoid= ee3bfb6efe254210VgnVCM1000008d0c1e0aRCRD\&vgnextchannel=ee3bfb6efe254210VgnVCM100000 8d0c1e0aRCRD\&vgnextfmt=default\&newLang=ca_ES Consultado a lo largo de todo el trabajo de investigación.

Institut d'Estadistica de Catalunya (IDESCAT). http://www.idescat.cat Consultado a lo largo de todo el trabajo de investigación.

Instituto Nacional de Estadística (INE). http://www.ine.es Consultado a lo largo de todo el trabajo de investigación.

ISS-SSI 2004. Derechos del niño en la adopción nacional e internacional: marco ético y orientaciones para la práctica. http://www.iss-ssi.org/Resourse_Centre/Guia_etica.PDF Consultado el 24/ 09/2009.

Khabibullina, L. 2008. "Circulación de los niños rusos. El caso de las adopciones transnacionales de Rusia a España". Comunicación en las jornadas La adopción internacional: el allá y el aquí. Experiencias y perspectivas. Barcelona: CIIMU.

Kirton, D. 2000. "Race", ethnicity and adoption. Filadelfia: Open University Press.

Lovelock, K. 2000. "Intercountry adoption as a migratory practice: a comparative analysis of intercountry adoption and immigratory policy and practice in the United States, Canada and New Zealand in the Post WWII period”. International Migration Review 34 (3): 907-949.

Marre, D. 2007. "I want her to learn her language and maintain her culture'. Transnational adoptive families' views of 'cultural origins', en Wade, P. (ed.), Race, ethnicity and nation. Perspectives from kinship and genetics: 73-93 Nueva York: Berghan Books.

Marre, D. y Bestard, J. 2004. "Sobre la adopción y otras formas de constituir familias. A modo de introducción", en Bestard, J. y Marre, D. (eds.) La adopción y el acogimiento. Presente y perspectivas: 17-71. Barcelona: Universidad de Barcelona.

Martínez Roig, A. 2004. "La adopción internacional". Cuadernos de pediatría social 5: 4-7.

Mateo, M. 1995. ¿Por Qué Adoptar en otro país? Guía para padres y profesionales. Madrid: CIES.

Melina, L. R. 2001. Cómo educar al niño adoptado. Consejos prácticos y alentadores para los padres adoptivos. Barcelona: Ediciones Médici.

Mirabent, V. y Ricart, E. (comps.) 2005. Adopción y vínculo familiar. Crianza, escolaridad y adolescencia en la adopción internacional. Barcelona: Paidós.

Morrier, G. 1995. Les stratégies identitaires des adolescents de l'adoption internationale appartenant à deux groupes racisés. Montréal: Université du Québec.

Ouellette, F. R. y Belleau, H. 1999. L'intégration familiale et sociale des enfants adoptés à l'étranger: recension des écrits. http://partenariat-familles.inrs-ucs.uquebec.ca Consultado 10-6-2008.

Ouellette, F. R. y Méthot, C. 2000. L'adoption tardive internationale. L'intégration familiale de l'enfant du point de vue des parents et des grands-parents. Montréal: Université du Québec.

Ouellette, F.R. y Saint-Pierre, J. 2008. "La quête des origines en adoption international". Informations sociales 146(2):84-91. www.cairn.info/revue-informations-sociales-2008-2-page-84.htm Consultado 16-7-2011.

Palacios, J. y Brodzinsky, D. 2010. "Adoption research: Trends, topics, outcomes". International Journal of Behavioral Development 34 (3): 270-284.

Panchón i Iglesias, C. yHeras i Trias, P. 2009. Adopcions sense receptes. Diferents maneres de viure l’adopció. Barcelona: Graó. 
Prat Carós, J. 2011. "La identidad” (en prensa).

Sætersdal, B. y Dalen, M. 2000 "Identity formation in a homogeneous country. Intercountry adoption in Norway", en Selman, P. (ed.), Intercountry adoption. Developments, trends and perspectives: 164-178. Londres: BAAF.

Sallesi i Doménech, C. 2008. "Niño soñado, niño real". Niños de boy 31: 6-12.

Selman, P. 2002. "Intercountry adoption in the new millennium: the "quiet migration" revisited". Population Research and Policy Review 21 (3): 205-225. http://dx.doi.org/10.1023/A:1019583625626 Consultado 1-3-2006.

Simon, R. J. y Alstein, H. 1981. Transracial adoption: a follow-up. Ashland, MD: Lexington Books.

Simon, R. J. y Alstein, H. 1987. Intercountry adoption: a multinational perspective. Nueva York: Praeger.

Simon, R. J. y Alstein, H. 1992. Adoption, race and identity: from infancy through adolescence. Nueva York: Praeger.

Sterett, S. 2002. "Introductory essay". Law E Society Review 36 (2): 209-226.

http://findarticles.com/p/articles/mi_qa3757/is_200201/ai_n9063380/Consultado 23-5-2011.

Tizard, B. y Phoenix, A. 1994. "Black identity and transracial adoption", enGaber, I. y J. Aldridge, J. (eds.), In the best interest of the child: culture, identity and transracial adoption: 89-102. Londres: Free Association Books.

Triseliotis, J. 1973. In Search of origins: the experience of adopted people. Nueva York: Beacon Press.

Triseliotis, J. 1991. "Intercountry adoption: a brief overview of the research evidence". Adoption and Fostering 15 (4): 46-52.

Vich, J. 2010. "Llegar a España: la circulación de menores en y desde China", en Fons, V., Piella, A. y Valdés, M. (eds.) Procreación, crianza y género. Aproximaciones antropológicas a la parentalidad: 261-278. Barcelona: PPU.

Vilaginés Ortet, C. 2007. L'altra cara de l'adopció. Aspectes emocionals que no s'expliquen. Barcelona: La esfera de los libros.

Volkman, T. A. 2003. "Introduction: transnational adoption". Social Text 74 (21/1): 1-5.

Volkman, T. A. (ed.). 2005. Cultures of transnational adoption. Durham: Duke University Press.

Wade, P. 2002. Race, nature and culture: an anthropological perspective. Londres: Pluto Press.

Weil, R. H. 1984. "International adoption. The Quiet migration". International Migration Review, 18(2): 276-293. http://www.asamst.ucsb.edu/courses/readingsAAS2/10_weil.pdf Consultado 1-4-2007.

Westhues, A. y Cohen, J. S. 1977. "A comparison of the adjustment of adolescent and young adult inter-country adoptees and their siblings". International Journal of Behavioral Development 20: 47-65.

Williams, I. 2003. Not quite/just the same/different: the construction of identity in Vietnamese war orphans adopted by white parents. Master of Arts by Thesis, University of Technology, Sydney. http://utsescholarship.lib.uts.edu.au/dspace/handle/2100/316 Consultado 28-2-2010.

Yngvesson, B. 2007. "Parentesco reconfigurado no espaço da adoção". Cadernos Pagu 29:111-138. http://www.scielo.br/scielo.php?script=sci_arttext\&pid=S0104-83332007000200006 Consultado 243-2011.

Yngvesson, B. 2010. Belonging in an adopted world. Race, identity and transnational adoption. Chicago: The University of Chicago Press.

Recibido: 22 de junio de 2012

Aceptado: 4 de marzo de 2013 